\title{
Retracted: Optimization of radiation modes in asymmetric planar slab optical waveguides
}

\author{
Sanjeev Kumar Raghuwanshi ${ }^{1 *}$, Virendra Kumar $^{1}$ and Radha Raman Pandey ${ }^{2}$
}

\begin{abstract}
Retraction
This article was mistakenly published twice. For this reason this duplicate article has now been retracted. For citation purposes please cite the original: http://www.inljournal.com/?_action=articlelnfo\&article=17

Abstract

In this paper, we try to optimize the substrate-radiation/substrate-cladding (cover) radiation modes in terms of their performance parameters. It is well known that the guided modes can only be normalized. However, the radiation modes can also be normalized using the delta/Dirac function. We try to optimize the waveguide design parameters for the known cases to achieve performance as good as guided modes. The formal electromagnetic theory is applied to study the radiation modes. The normalization condition on radiation mode has been carefully used during analysis. The results are found to be satisfactory. It has been concluded that we can modify the performance of radiation modes according to our requirements. The performance is compared with the guided mode. The paper discusses guidelines to optimize the radiation modes for various constraints.
\end{abstract}

Keywords: Leaky, Radiation, Optimized, Guided, Asymmetric

\section{Background}

Radiation modes are useful to study the power leakage loss and to design passive wavelength division multiplexing (WDM) fiber optic network components. Lots of power can flow through the substrate and cover regions. These radiation modes are useful not only to design fiber optic coupler and WDM optical network components, but also to predict the power loss in various passive WDM optical network components. It is inevitable to find out the optimum waveguide design parameters for the purpose to achieve a better device performance $[1,2]$. We need to optimize these modes to avoid the leakage of power in optical communication systems.

By choosing the appropriate waveguide design parameters, it is possible to perfectly match the radiation modes at the interfaces [3-9]. In fact, the radiation modes can be completely removed at the interfaces, which may not be possible even with guided modes.

\footnotetext{
*Correspondence: sanjeevrus@yahoo.com

'Department of Electronics Engineering, Indian School of Mines, Dhanbad, 826004, India

Full list of author information is available at the end of the article
}

\section{Methods}

Optimization of substrate/cover radiation modes

We implicitly assumed the rectangular coordinate system having refractive index variation in the $x$-direction. The wave is propagating in the $z$-direction, and the medium is infinite in the $y$-direction (no refractive index variation). We consider $n_{\mathrm{c}}, n_{\mathrm{s}}$, and $n_{\mathrm{f}}$ as the refractive index of cover, substrate, and film regions, respectively. Since the phase constant $\beta$ for the substrate radiation mode is in the range of (free space wave number $k_{0}$ )

$$
k_{0} n_{\mathrm{c}}<\beta<k_{0} n_{\mathrm{s}}
$$

The $x$-direction transverse wave-vector $k$ in the substrate satisfies [1,2],

$$
0 \leq \kappa \leq k_{0} \sqrt{n_{\mathrm{s}}^{2}-n_{\mathrm{c}}^{2}}
$$

Here, subscripts s, c, f, and $\mathrm{r}$ are used to denote the substrate, cover, film, and radiation mode, respectively. After applying the continuity condition for the tangential electromagnetic field components at the interfaces, the lateral electromagnetic fields are obtained as follows: 
Here, the lateral electromagnetic field distribution function $\Phi_{r}\left(x, \rho_{s}\right)$ would be $[1,2]$

$$
\begin{aligned}
& \phi_{r}\left(x, \rho_{\mathrm{s}}\right)= \\
& \frac{1}{\sqrt{D_{\mathrm{r}}}}\left\{\begin{array}{l}
e^{-\alpha_{\mathrm{c}} x}, \\
\cos \left(\sigma_{\mathrm{f}} x\right)+B_{\mathrm{rf}} \sin \left(\sigma_{\mathrm{f}} x\right),-t \leq x \leq 0 \\
A_{\mathrm{rs}} \cos \{\kappa(x+t)\}+B_{\mathrm{rs}} \sin \{\kappa(x+t)\}, y \leq-t
\end{array}\right.
\end{aligned}
$$

$\underset{\sigma_{\mathrm{f}}}{\text { where }}=\sqrt{k_{0}^{2}\left(n_{\mathrm{f}}^{2}-n_{\mathrm{s}}^{2}\right)+\kappa^{2}}$

$$
\alpha_{\mathrm{c}}=\sqrt{k_{0}^{2}\left(n_{\mathrm{s}}^{2}-n_{\mathrm{c}}^{2}\right)-\kappa^{2}} \text {. If the normalization factor }
$$

$D_{\mathrm{r}}$ is

$$
D_{\mathrm{r}}=\frac{\pi}{2}\left(A_{\mathrm{rs}}^{2}+B_{\mathrm{rs}}^{2}\right)
$$

The distribution function satisfies the orthonormality condition,

$$
\int_{-\infty}^{+\infty} \phi_{\mathrm{r}}\left(x, \rho_{\mathrm{s}}\right) \phi_{\mathrm{r}}\left(x, \rho_{\mathrm{s}}^{\prime}\right) d x=\delta\left(\rho_{\mathrm{s}}-\rho_{\mathrm{s}}^{\prime}\right)
$$

where $\delta\left(\rho_{\mathrm{s}}-\rho_{\mathrm{s}}^{\prime}\right)$ is the Dirac delta function. Figures 1 and 2 show the various calculations done on the substrate radiation modes. From Figure 1, it is apparent that the film-cover region is perfectly matched, but not the film-substrate region. The film thickness $h=5 \mu \mathrm{m}$ is considered in all calculations. The refractive indexes are $n_{\mathrm{f}}=1.50, n_{\mathrm{s}}=1.45$, and $n_{\mathrm{c}}=1.40$, and the operating wavelength is $\lambda=1.55 \mu \mathrm{m}$. The aim is to match or avoid the substrate-film radiation modes. The computation has been carried out for the various values of the transverse wave-vector for optimization purposes. The substrate radiation mode has been completely eliminated on $\kappa=1.0712 \times 10^{4} \mathrm{~cm}^{-1}$. This is shown in Figure 2a.

In this case, there is no leakage loss, and practically, it can be used for designing the lossless WDM optical network components. In fact, this particular mode will suffer a lesser amount of leakage loss compared to guided modes. The substrate radiation mode has been perfectly matched while on $\kappa=1.2242 \times 10^{4} \mathrm{~cm}^{-1}$, which is shown in Figure 2b. Practically, this may be useful to design the WDM network components for phase-matching applications.

Figure 3 shows the mode amplitude difference between the substrate-film interfaces. Hence, computational accuracy has been tested.

The radiation mode is almost perfectly matched at $\kappa=1.2242 \times 10^{4} \mathrm{~cm}^{-1}$, where the mode amplitude difference between the substrate-film regions approaches to zero. These waveguide design parameters are important to achieve the optimum performance.

\section{Results and discussion}

Since the phase constant $\beta$ for the substrate-cladding radiation is in the range of [3-6]

$$
0 \leq \beta \leq k_{0} n_{\mathrm{c}}
$$

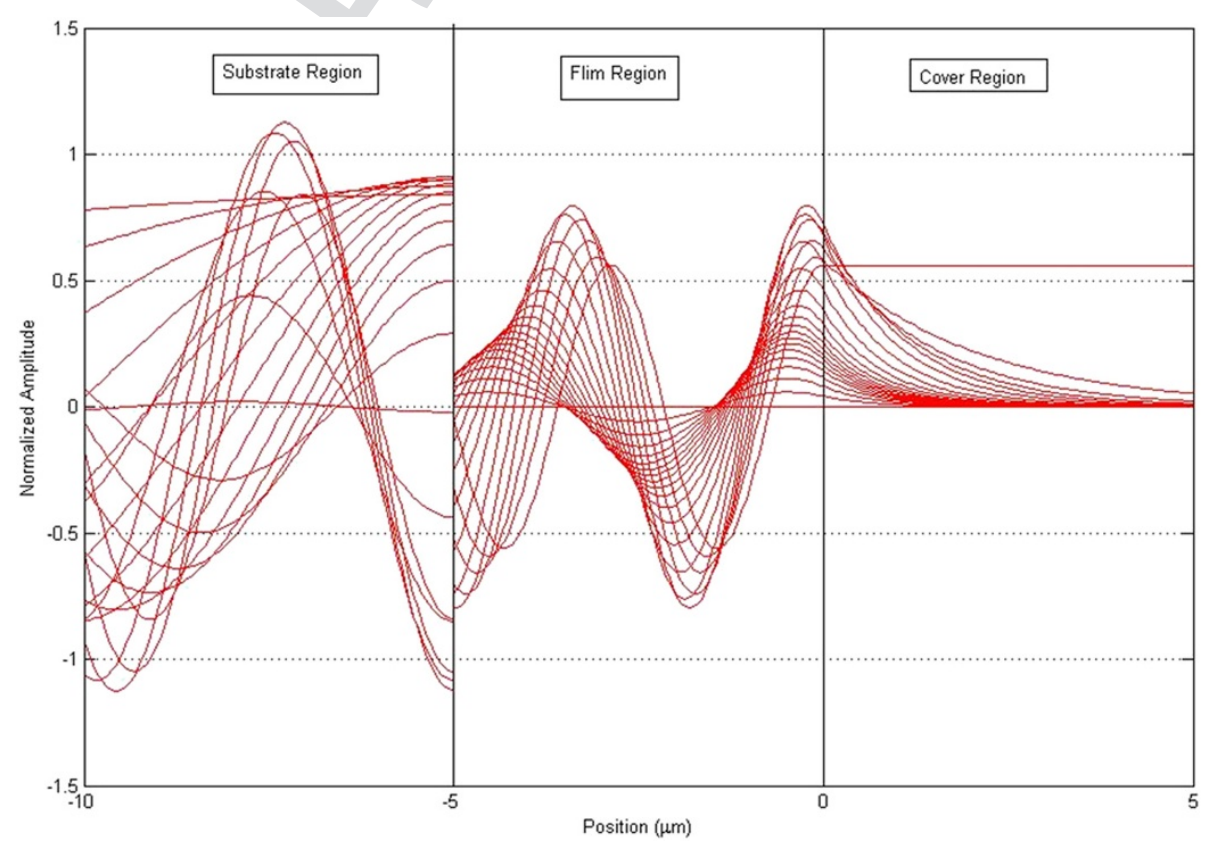

Figure 1 Normalized substrate radiation modes for various values of the transverse wave-vector. 

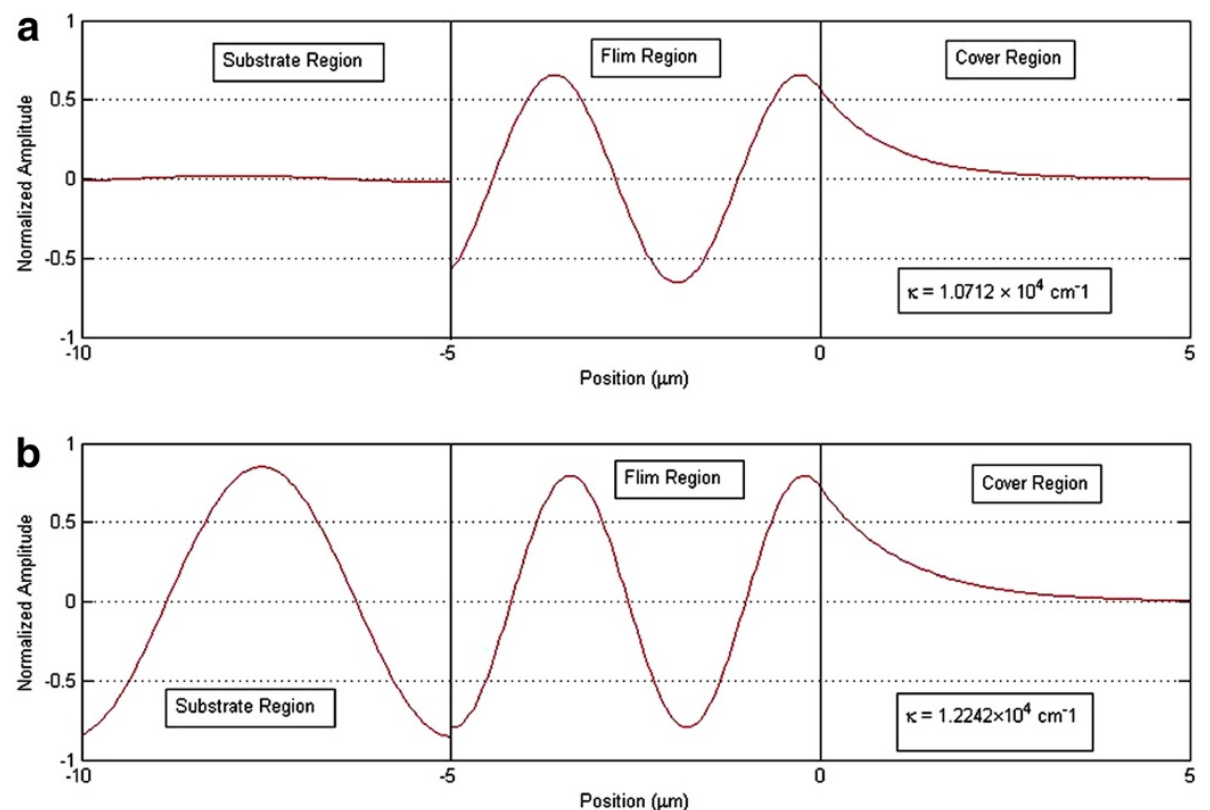

Figure 2 Elimination and matching of the substrate radiation mode. (a) The substrate radiation mode has been completely eliminated. (b) The substrate radiation mode is almost matched with the film region.

in this case, the $x$-direction transverse phase constant $\kappa$ in the substrate satisfies

$$
k_{0} \sqrt{n_{\mathrm{s}}^{2}-n_{\mathrm{c}}^{2}} \leq \kappa \leq k_{0} n_{\mathrm{s}}
$$

so that $\beta$ is a pure imaginary number. In other words, the radiation mode may be propagated, in which case $\kappa$ is given by Equation 2, or may not be propagated, in which case $\kappa$ is given by Equation 7. The solution of wave equation for the substrate-cladding radiation mode is discussed in detail elsewhere [1]. The simulation results are the same, except that the range of $\beta$ has been changed. Figure 4 shows that neither the filmsubstrate nor the film-cover regions are matched. These modes are not useful for any practical purpose. Several trials have been performed to match the interfaces and to search out the optimum waveguide design parameters. This case is even more crucial because there are

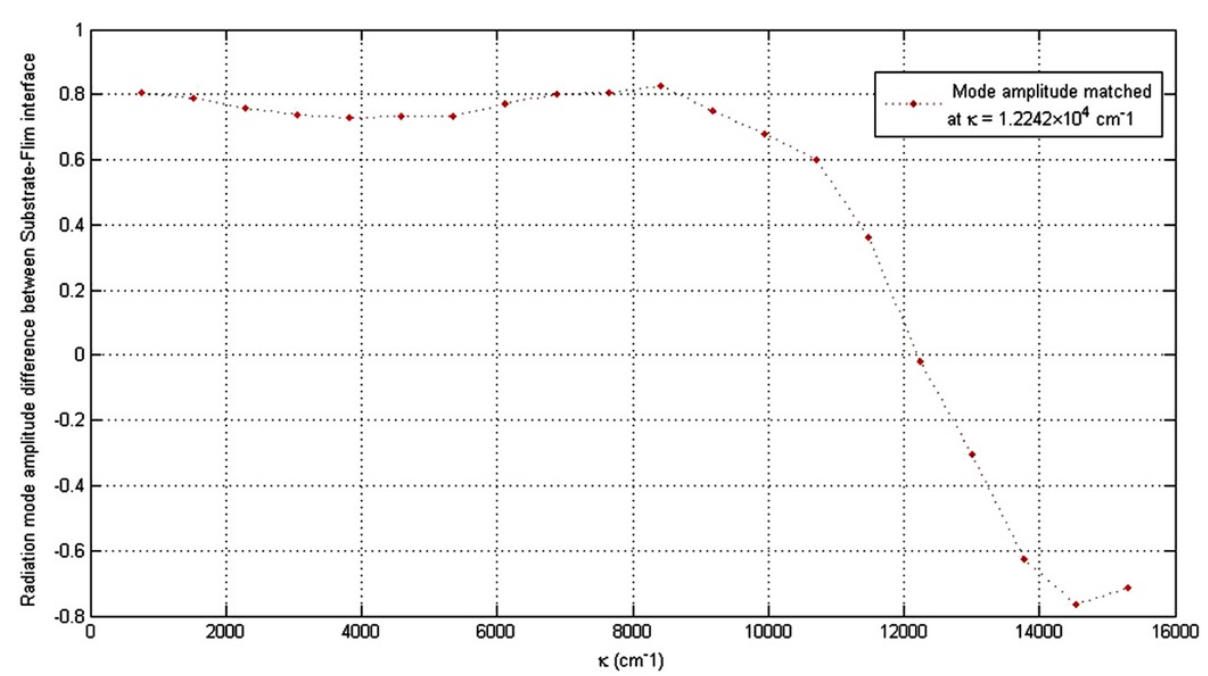

Figure 3 Mode amplitude difference versus transverse wave-vector $\kappa\left(\mathrm{cm}^{-1}\right)$. 


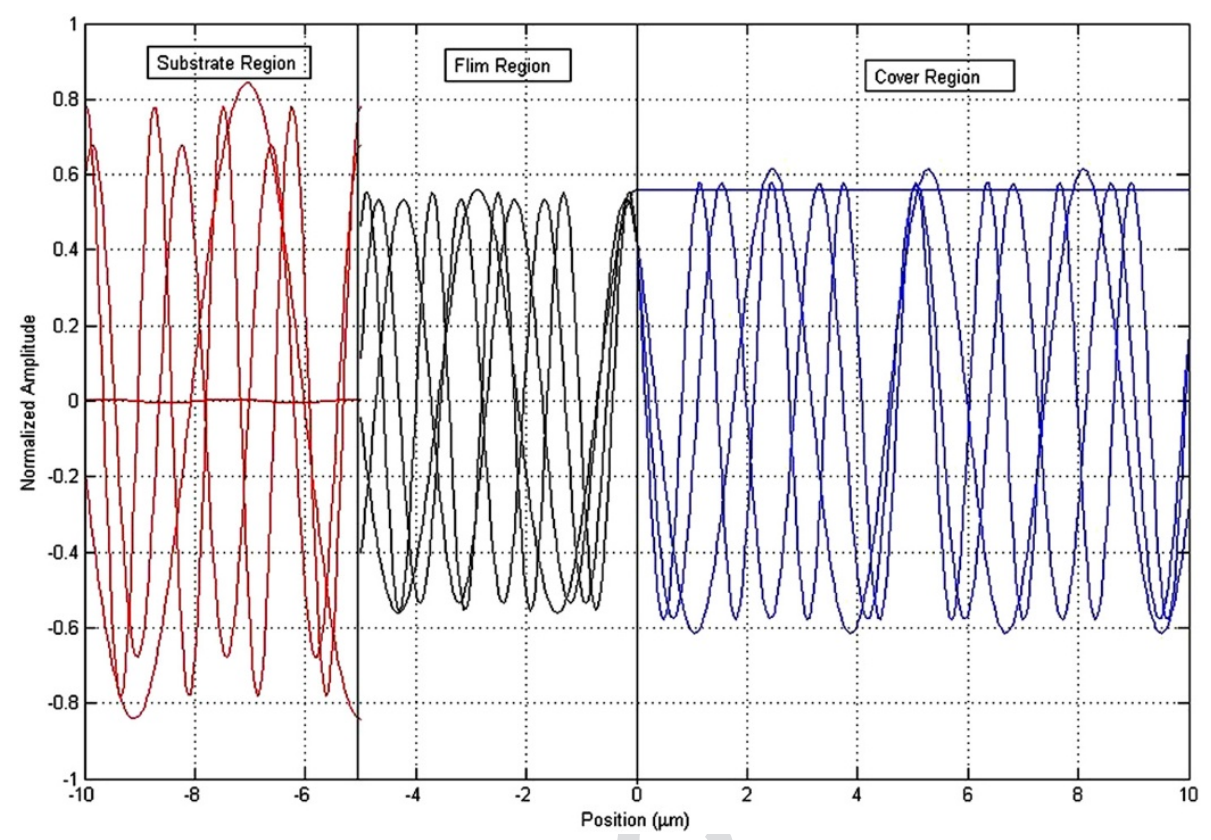

Figure 4 Normalized substrate-cover radiation modes for various values of the transverse vector.

two non-matching interfaces. From Figure 4, it is apparent that the light is being guided in both the substrate and cover regions. Hence, more power will flow in the cover as well as substrate regions. For any practical application, these radiation modes need to be optimized.
Figure 5 shows the various calculations done on the substrate-cover radiation mode. It has been found, as shown in Figure $5 \mathrm{a}$, that at $\kappa=2.7058 \times 10^{4} \mathrm{~cm}^{-1}$, the substrate-film radiation mode is completely removed; however, the film-cover region is properly matched. In
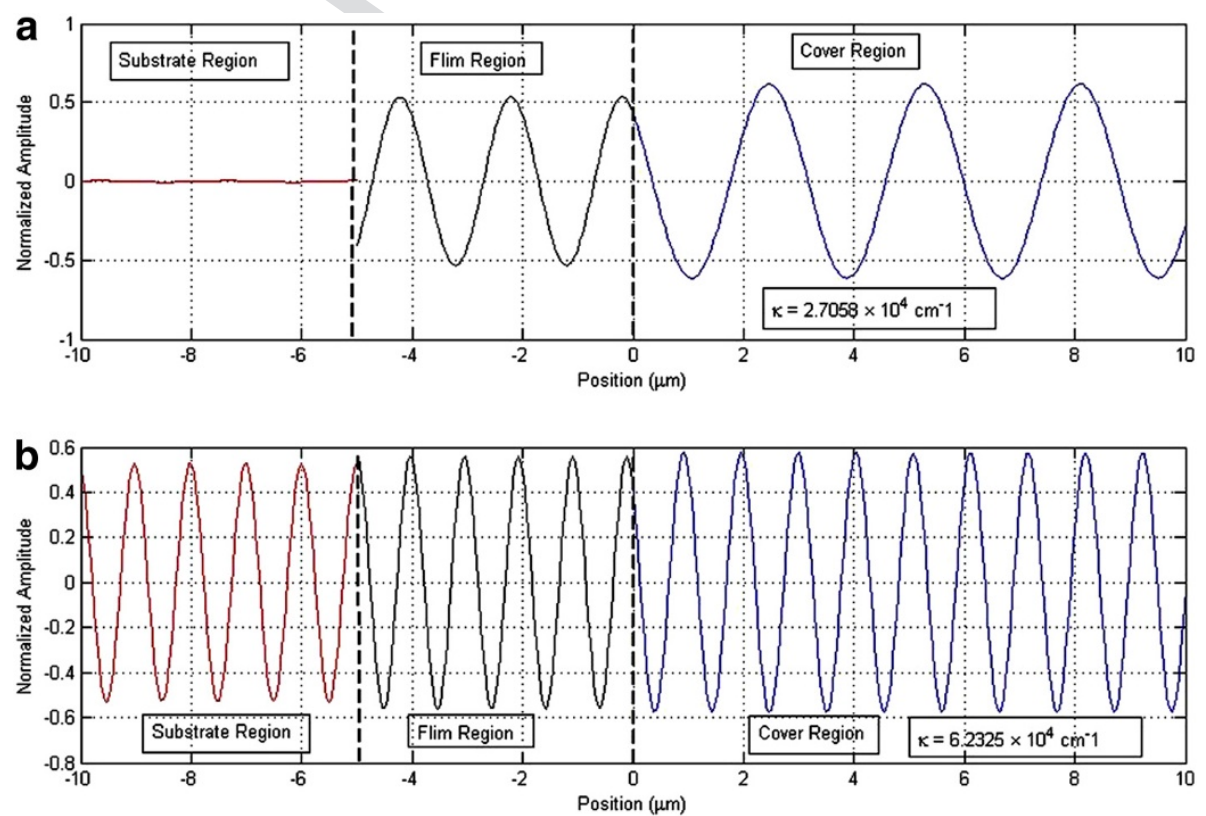

Figure 5 Elimination of the substrate-film radiation mode and matching of the substrate radiation mode (a, b). 
another observation, as shown in Figure 5b, the substrate radiation mode is perfectly matched with both regions at $\kappa=6.2325 \times 10^{4} \mathrm{~cm}^{-1}$. These design guidelines are very useful to achieve the desirable performance.

\section{Conclusions}

Formal electromagnetic theory has been applied on asymmetric waveguide structure to find out the eigen value equation for the given cases. The mode orthogonality condition has been proved unconditionally, while it has been carefully used in every aspect during the calculation. The asymmetric waveguide structure shows the non-uniform power variation in each region. The modes are not matched always for the given design parameter. In this paper, radiation modes are optimized without giving much mathematical treatment. The techniques of mode optimization were found to be satisfactory. It has been shown through analysis that we can either eliminate the substrate radiation mode or totally match the substrate radiation mode with the film region. These design guidelines on radiation modes are very important for the purpose of designing a low-loss waveguide coupler, mode isolator, mode phase-matching circulator, and other types of WDM components.

\section{Competing interests}

The authors declare that they have no competing interests.

\section{Authors' contributions}

SKR carried the simulation work, sequence alignment, and drafted the manuscript. VK checked the validity of the simulations results and compiled the manuscript. RRP checked the grammatical and spelling mistakes. All authors read and approved the final manuscript.

\section{Authors' information}

SKR is working as an assistant professor in the Department of Electronics Engineering at Indian School of Mines, Dhanbad. He received his bachelor's degree in Electronic and Instrumentation Engineering from S.G.S. I.T.S. Indore, Madhya Pradesh, India and his master's degree in Solid State Technology from the Indian Institute of Technology, Kharagpur. Since July 2009, he has obtained his Ph.D. degree in the field of optics from the Department of Electrical Communication Engineering of the Indian Institute of Science, Bangalore, India. He is the author of one book entitled Analytical and Numerical Study of Propagation in Optical Waveguide and Devices in Linear and Non-linear Domain published by VDM Verlag, Germany in 2009. His current research interest includes homogeneous optical waveguide and nonlinear optics.

VK received his Ph.D. in 1980 and is presently working as a professor and head of the Department of Electronic Engineering, Indian School Mines, Dhanbad. He has published over 70 research papers in the reputed international and national journals and presented about 80 research papers in different national and international conferences. He has also authored two books entitled Electronic and Thermal Properties of Semiconductors: Plasmon Approach and Design of a Low Cost Wireless Sensor Network published by VDM Verlag, Germany in 2010. He gave number of seminar talks in UK, Italy, Portugal, Malaysia, Singapore, and USA. He has completed a number of R\&D projects and organized a number seminars and short term courses. RRP is working as an associate professor and head in the Department of Electronics and Communication Engineering at the Institute of Engineering and Industrial Technology, Malandighi, Durgapur, India. He received his (B.E.) degree in Electronic and Communication Engineering from MJP Rohilkhand University, Bareilly, Uttar Pradesh, India and his Master of Technology (M.
Tech) degree in VLSI Design from Uttar Pradesh Technical University, Lucknow, India. He is pursuing his Ph.D. degree in the field of Modeling of WDM Optical Network Components from the Department of Electronics Engineering of the Indian School of Mines, Dhanbad, India. His current research of interest is modeling of WDM optics.

\section{Author details}

'Department of Electronics Engineering, Indian School of Mines, Dhanbad, 826004, India. ${ }^{2}$ Department of Electronics and Communication Engineering Institute of Engineering and Industrial Technology, Durgapur, 713212, India.

Received: 30 September 2010 Accepted: 5 March 2012

Published: 5 March 2012

\section{References}

1. Marcuse, D: Theory of Dielectric Waveguides. McGraw Hill Inc., New York (2003)

2. Koshiba, M: Optical Waveguide Analysis. McGraw Hill Inc., New York (1992)

3. Yeh, C: Elliptical dielectric waveguides. J. Appl. Phys. 33, 3235 (1962)

4. Ghatak, AK, Thyagarajan, K: Optical Electronics. Cambridge University Press, Cambridge (2007)

5. Mishra, P, Sharma, A: Analysis of single mode inhomogeneous planar waveguides. IEEE J. Lightwave Technol. 4, 204 (1986)

6. Raghuwanshi, SK, Talabattula, S: Analytical approximation solutions for 3-D optical waveguides: review. Indian J. Phys. 83, 1 (2009)

7. Thyagarajan, K, Diggavi, S, Ghatak, AK: Analytical investigations of leaky and absorbing planar structure. Op. Quantum. Electron 9, 131 (1987)

8. Scarmozzino, R, Gopinath, A, Pregla, R, Helfert, S: Numerical techniques for modeling guided-wave photonic devices. IEEE J of Selected Topics in Quantum Electron. 6(1), 150-162 (2000)

9. Raghuwanshi, SK: Comparative study of asymmetric versus symmetric planar slab dielectric optical waveguides. Indian J. Phys. 84(7), 831 (2010)

doi:10.1186/2228-5326-2-2

Cite this article as: Raghuwanshi et al:: Retracted: Optimization of radiation modes in asymmetric planar slab optical waveguides. International Nano Letters 2012 2:2.

\section{Submit your manuscript to a SpringerOpen ${ }^{\odot}$ journal and benefit from:}

- Convenient online submission

- Rigorous peer review

- Immediate publication on acceptance

- Open access: articles freely available online

- High visibility within the field

- Retaining the copyright to your article

Submit your next manuscript at $>$ springeropen.com 